Br Heart f 1985; 53: 353-62

\title{
Editorial
}

\section{Mitral valve prolapse associated with other disorders Casual coincidence, common link, or fundamental genetic disturbance?}

\author{
ALASDAIR D MALCOLM \\ From Airedale General Hospital, Keighley, West Yorkshire
}

Clinicians seem to enjoy describing associations between diseases, abnormalities, and features in patients they have examined. Indeed the recognition of such links is an understandable consequence of good observational powers allied to thoughtful consideration of accumulated experience and data. As mitral valve prolapse ${ }^{1-4}$ is now recognised as a fairly common clinical entity ${ }^{3-8}$ it comes as no surprise to find that a substantial number of published reports has accumulated linking it with a variety of other clinical conditions. With echocardiographically demonstrable mitral valve prolapse recently documented in one large study in the Eastern part of the United States in $5 \%$ of a total of 4967 people with technically adequate echocardiograms, ${ }^{9}$ we can expect that chance occurrence of mitral valve prolapse with other disorders will not be too infrequent. ${ }^{3}$ It is the purpose of this editorial to consider the reported associations and, with an awareness of the possibility of casual coincidence, categorise the associations according to pathophysiological mechanisms wherever possible.

\section{Screening}

Although there are certain auscultatory features characteristic of mitral valve prolapse, ${ }^{2-410}$ there is a subjective element and considerable interindividual variation in what is heard through the stethoscope, and surveys of the prevalence of mitral valve prolapse could not depend on auscultatory criteria. In addition, silent mitral valve prolapse is not rare,,$^{310-12}$ and non-ejection systolic clicks can be heard without echocardiographically demonstrable mitral valve prolapse. ${ }^{310}$ The direct but non-invasive visualisation of excessive systolic bulging of the mitral leaflets by echocardiography has been the key to the widespread diagnosis of the condition ${ }^{31314}$ and it is on echocardiographic data that surveys of the prevalence of

Requests for reprints to Dr Alasdair D Malcolm, Airedale General Hospital, Steeton, Keighley, West Yorkshire BD20 6TD. mitral valve prolapse are largely based. ${ }^{3-10}$ Nevertheless, the distinction between mitral valve prolapse and certain movements of the mitral valve that may be normal is imprecise, ${ }^{13}$ and some investigators may even have been overdiagnosing prolapse. ${ }^{15}$ Moreover, in some subjects it may be a variant of normal ${ }^{16}$ and present only at certain times of life. ${ }^{9}$

M mode echocardiography will not detect mitral valve prolapse in a significant percentage of subjects shown by angiography to have mitral valve prolapse or with auscultatory signs of the conditions $s^{3} 10111718$ because of the limited view it affords of mitral valve motion. 13141718 False positive patterns of mitral valve prolapse can also be found, ${ }^{3} 131718$ but this is much less of a problem than the false negatives. Cross sectional echocardiography undoubtedly provides better spatial orientation and ease of determining the mitral annular plane than the $M$ mode method and should now be considered the standard for diagnosis. ${ }^{1314} 17^{-19} \mathrm{It}$ is more sensitive than $M$ mode and highly specific, ${ }^{17-19}$ and the sensitivity can be enhanced by using selected combinations of echocardiographic signs. ${ }^{19}$ Doppler echocardiography can detect associated mitral regurgitation but a mid to late systolic flow signal posterior to the mitral valve may be indicative of blood movement within the prolapsed leaflet ${ }^{18}$; more work is needed to discover the true value of duplex imaging with range gated Doppler flow detection in the assessment of and screening for mitral valve prolapse.

All surveys of the prevalence of mitral valve prolapse that have relied primarily on $M$ mode echocardiographic criteria must be considered as likely to have underestimated the prevalence and we should now require data derived from cross sectional echocardiography, analysing multiple features. ${ }^{14} 19$

\section{Classical pathology}

In primary or idiopathic mitral valve prolapse ${ }^{3}$ the 
voluminous leaflets are structurally abnormal with myxomatous degeneration and disruption of the pars fibrosa, and there is dilatation of the mitral annulus. ${ }^{320-27}$ There is evidence of an abnormality of collagen. 232628 The dissolution or dysgenesis of collagen in the continuous complex of pars fibrosa and chordae appears to be the basic mechanism responsible for the ballooning of the mitral leaflets. ${ }^{4}$ It remains uncertain, however, as to whether the fundamental problem is a dyscollagenosis ${ }^{26}$ or whether the collagen abnormalities and superimposed glycosaminoglycan infiltration giving the tissue its myxomatous appearance can develop in a valve that originally was structurally and histologically normal but for some reason prolapsed and thereby altered the magnitude and distribution of mechanical forces acting on the leaflet, annulus, and chordae. 23262829 The chordal deficiencies described by Becker and de Wit as being very common in mitral valve prolapse and relatively uncommon with normal non-prolapsing mitral valves ${ }^{30}$ may also render the leaflets more vulnerable to mechanical damage.

This general pattern of abnormality in prolapsing mitral valves that become available for pathological examination, either by surgical excision because of severe mitral regurgitation requiring valve replacement or by death and subsequent necropsy, cannot be assumed to be the norm in all cases of mitral valve prolapse. The Framingham study data have provided powerful evidence that echocardiographic mitral valve prolapse can be a transient phenomenon at a certain stage in life, at least for women. ${ }^{9}$ The prevalence of mitral valve prolapse (by $M$ mode echocardiography screening, with cross sectional echocardiography for confirmation in more than $90 \%$ of subjects) declined progressively for successive decades from $16.9 \%$ for women in their twenties through $12.2 \%$ in their forties and $4.4 \%$ in their sixties to $1.4 \%$ for women of 80 years and older. In contrast, the prevalence among men showed no particular age related trend and averaged about $3 \%$. It seems unlikely that structural abnormalities would be present in the mitral valves of a significant proportion of younger women and similarly unlikely that these would be remedied in most as they get older. Rather, we should look to factors beyond the mitral valve itself, and age related changes in left ventricular size, shape, or wall movement may be part of the explanation.

In evaluating possible associations between mitral valve prolapse and various disorders we must bear in mind that an echocardiographically prolapsing mitral valve is not necessarily abnormal in any way ${ }^{13} 1416$ and draw realistically limited conclusions in those conditions in which cardiac tissue has not been available for systematic pathological and biochemical study in surgical or necropsy series.
Association with abnormalities of left ventricular size, shape, or function

Excessive bulging of one or both mitral leaflets into the left atrium may be due to factors other than floppy leaflets, elongated chordae, or a dilated annulus. ${ }^{313} 3132$ Thus disturbance of the normal balance between ventricular and valvar size may cause anatomical prolapse in the absence of any pathological feature of mitral leaflets or chordae. This would occur when left ventricular size is sufficiently reduced or shape sufficiently altered that maintenance of normal leaflet position and contour during systole is impossible and some degree of prolapse into the left atrium results, as in hypertrophic obstructive cardiomyopathy. ${ }^{332}$ In secundum atrial septal defect, where up to half the patients seem to have mitral valve prolapse, ${ }^{31333} 34$ the reduced left ventricular size with distorted ventricular geometry is probably often responsible for the mitral valve prolapse. ${ }^{13} 34$ There are, however, instances where the mitral valve has become severely regurgitant and been found to have the myxomatous degeneration characteristic of primary mitral valve prolapse. ${ }^{335}$ Distortion of the atrioventricular area and reduced left ventricular size have been proposed as the mechanism of prolapse in patients with progressive muscular dystrophy and straight or lordotic thoracic spines. ${ }^{36}$ Ischaemically induced disturbance of contractile function in papillary muscles or subjacent myocardium may result in failure to maintain chordal systolic tension and so prolapse ensues ${ }^{32} 37$; this would be the most common cause of secondary mitral valve prolapse. Disturbance of left ventricular contraction with previous rheumatic carditis or viral myocarditis or with congestive cardiomyopathy may result in prolapse. ${ }^{37}$ It has also been proposed that the abnormal sequence of ventricular activation in the Wolff-Parkinson-White syndrome can give rise to mitral valve prolapse. ${ }^{37} 38$ but the idea that the bypass tract and prolapse are associated structural malformations within the atrioventricular region is an alternative explanation. ${ }^{3}$

Secondary mitral valve prolapse is probably of no special significance in most subjects, but it has been suggested that an abnormally stressed mitral valve might ultimately develop the same pathological changes found in primary mitral valve prolapse. ${ }^{13}$ Nevertheless, when secundum atrial septal defect is accompanied by a regurgitant prolapsing mitral valve the differential diagnosis with primum atrial septal defect complicated by atrioventricular valve abnormality has to be considered and there may be surgical implications. ${ }^{3}$ Infective endocarditis, which hardly ever occurs in isolated secundum atrial septal defect, can occur when associated mitral valve prolapse is present, and Jeresaty recommends antibiotic 
prophylaxis for secundum atrial septal defect with mitral valve prolapse and late systolic or pansystolic murmurs. ${ }^{3}$ Perhaps it would be prudent to follow the same guidelines for secondary mitral valve prolapse in ischaemic heart disease. ${ }^{37}$

\section{Association with congenital heart disease}

Secundum atrial septal defect is the commonest reported association, as discussed in the previous section, but there are a variety of other congenital cardiac abnormalities in which an association with mitral valve prolapse has been claimed. ${ }^{337} \mathrm{~A}$ retrospective study of M mode echocardiograms from 120 adults with congenital heart disease revealed mitral valve prolapse in nine of $32(28 \%)$ patients with secundum atrial septal defect, in none of five with primum atrial septal defect, in 10 of $25(40 \%)$ with ventricular septal defect, in five of seven $(71 \%)$ with persistent ductus arteriosus, in three of five $(60 \%)$ with tetralogy of Fallot, in five of $15(33 \%)$ with pulmonary stenosis, in two of $14(15 \%)$ with left ventricular outflow obstruction, in two of three (67\%) with Ebstein's anomaly, and in four of $14(29 \%)$ with miscellaneous other defects. ${ }^{33}$ Among 45 children with $M$ mode echocardiographically demonstrated mitral valve prolapse there were three cases of ventricular septal defect, one of persistent ductus arteriosus, and two of hypertrophic obstructive cardiomyopathy. ${ }^{39}$

Pathological studies have provided some interesting data in respect of ventricular septal defect and Ebstein's anomaly. Among 112 hearts with isolated ventricular septal defect collected over a 30 year period and restudied specifically for gross and microscopic (significant thickening of the spongiosal layer and invasion and disruption of the fibrosa by the spongiosa) evidence of mitral valve prolapse there was an overall incidence of the condition of $18 \% .^{40}$ There was no significant difference in the incidence of mitral valve prolapse for the three age groups $(<1$ year, $1-16$ years, and 17-91 years) considered. Spongiosal invasion of the fibrosa was fully developed by 3 months of age, and there was no evidence that the incidence or severity of spongiosal invasion increased between the ages of 3 months and 88 years. In no patient was the mitral valve prolapse considered to be the cause of death. Complications of the prolapse in terms of ruptured chordae, endocarditis, mitral regurgitation, and fibrin deposits at the mitral valve-left atrial angle occurred at approximately the same frequency as that reported in necropsy studies of isolated mitral valve prolapse. In the specimens with prolapse $63 \%$ also had similar involvement of the tricuspid valve, $16 \%$ of the pulmonary valve, and $5 \%$ of the aortic valve. In a separate study the hearts obtained at necropsy from 10 patients with Ebstein's anomaly of the tricuspid valve were examined for mitral valve prolapse and the condition was found in none of five hearts from patients aged 1 day to 10 months but in 3 of 5 hearts from patients aged 18 to 72 years. ${ }^{41}$ The most severe degree of prolapse occurred in the 18 year old, whose mitral valve histology showed myxomatous change with a pronounced increase in acid mucopolysaccharide material in the leaflets. ${ }^{42}$ These pathological studies would potentially have underestimated the frequency of mitral valve prolapse with congenital cardiac abnormalities for they depended on necropsy specimens, and mitral valve prolapse secondary to disturbances of left ventricular dynamics, ${ }^{31}$ as in secundum atrial septal defect, ${ }^{34}$ would have been missed.

\section{Association with other cardiac structural abnor- malities}

Tricuspid valve prolapse coexists fairly frequently with mitral valve prolapse, as shown at necropsy, ${ }^{322}$ on cineangiography,,$^{34344}$ and by $M$ mode $^{34546}$ and cross sectional echocardiography. 174748 For example, in 61 symptomatic patients with auscultatory signs of mitral valve prolapse and no significant occlusive disease on selective coronary arteriography left ventricular angiography detected prolapse in $52(84 \%)$, and right ventricular angiography showed tricuspid valve prolapse in $32(52 \%)$; in nine cases prolapse involved the tricuspid valve alone. Although $21 \%$ of a group of 53 patients with mitral valve prolapse had concomitant tricuspid valve prolapse on $M$ mode echocardiography, imaging of the tricuspid valve by this technique is inconsistent and cross sectional echocardiography is more often successful and provides better visualisation of the tricuspid leaflets. ${ }^{1748}$ Thus cross sectional echocardiography showed concomitant tricuspid prolapse in $48 \%$ of 64 patients with mitral valve prolapse ${ }^{17}$ and in $19 \%$ of 31 patients with mitral valve prolapse. ${ }^{48}$ Contrast echocardiography is helpful in evaluating tricuspid regurgitation in this situation. ${ }^{1747}$ The general observation has been made that among subjects with tricuspid valve prolapse a more severe form of mitral valve prolapse is prevalent. ${ }^{17}$ Although it has been claimed that tricuspid valve prolapse occurs rarely as an isolated lesion, ${ }^{3}$ careful cross sectional echocardiographic technique has been shown to be capable of demonstrating it in $6 \%$ of an assortci group of 112 subjects without mitral valve prolapse, ${ }^{48}$ and it can be shown angiographically when prolapse is not evident on the contralateral ventricular cineangiogram. ${ }^{44}$ Data are lacking on the histological state of prolapsing tricuspid valves where there has not been concomitant mitral valve prolapse but the prolapse may be secondary to disturbed right ventricular dynamics. A genetically determined abnormality of atrioventricular valve development or 
maintenance or both would explain dual valvar involvement.

Aortic valve prolapse was evaluated by cross sectional echocardiography in 50 subjects with mitral valve prolapse and no stigmata of Marfan's syndrome. ${ }^{47}$ Twelve (24\%) subjects had redundant aortic leaflets bulging into the left ventricular outflow tract during diastole, and most of these subjects also had aortic regurgitation. In one subject who underwent mitral and aortic valve replacement for severe heart failure both excised valves showed characteristic myxomatous degeneration. In an earlier study of 112 subjects with mitral valve prolapse successful cross sectional detailed imaging of the aortic valve was achieved in 77 and a prolapse pattern identified in 17 (22\%), 16 of whom showed increased echo reflection from aortic leaflet tissue and four of whom had aortic regurgitation. ${ }^{17}$ The aortic root measurement on $M$ mode echocardiography was normal in the 60 subjects with mitral valve prolapse without aortic valve prolapse but enlarged in six of the 17 subjects with both aortic valve and mitral valve prolapse. Other evidence of myxomatous involvement of the aortic valve in some cases of mitral valve prolapse has been reported with aortic leaflets thickened or folded on cross sectional echocardiograms, systolic oscillation and multiple leaflet echoes on $M$ mode scans, and confirmation of the myxomatous nature of one aortic valve replaced at operation. ${ }^{49}$ The myxomatous degeneration $^{25}$ which typifies primary mitral valve prolapse is therefore not confined to atrioventricular valve tissue in certain individuals, and comprehensive clinical evaluation of the subject with mitral valve prolapse should be conducted with this in mind. Cross sectional echocardiography is the major tool for precise evaluation of this sort ${ }^{17} 47$ and may even show triple valve involvement. ${ }^{47}$

Atrial septal aneurysm combined with mitral valve prolapse has been found at necropsy in two patients, ${ }^{50}$ but no mention was made of myxomatous degeneration in the leaflet tissue. Bulging of the aneurysm can be seen on cross sectional echocardiography, and there is a report of five patients with the combined conditions, four of whom also had tricuspid valve prolapse. $^{51} \mathrm{~A}$ developmental abnormality affecting the tissue of interatrial septum and mitral valve can be supposed. 5051

There are a number of reports of a definite association between pre-excitation atrioventricular pathways and mitral valve prolapse. ${ }^{3} 373852-55$ The relation with the Wolff-Parkinson-White syndrome was first reported by Gallagher $e t$ al in 1975 with seven cases of mitral valve prolapse among 68 patients with the Wolff-Parkinson-White syndrome and attacks of arrhythmia that were sufficiently frequent or of such severity as to be disabling or life endangering. ${ }^{52}$ The
Lown-Ganong-Levine syndrome has been found in association with mitral valve prolapse in several instances. ${ }^{353-55}$ Of 12 patients with paroxysmal supraventricular tachycardia, three had the LownGanong-Levine syndrome, one the WolffParkinson-White syndrome type A, and eight normal electrocardiograms. ${ }^{54} \mathrm{Six}$ of the eight patients with normal electrocardiograms were, however, shown on electrophysiological study to have atrioventricular bypass tracts. This evidence suggests that supraventricular tachycardia in patients with mitral valve prolapse could often be related to bypass tracts that, if the surface electrocardiogram is normal, will require special electrophysiological studies to enable diagnosis, and the authors felt that there may be a developmental link between the consistently left sided bypass tracts and the mitral valve prolapse. ${ }^{54}$ These data from patients with major arrhythmia problems ${ }^{52} 54$ have to be kept in perspective when dealing with subjects with mitral valve prolapse and little or no symptomatology of this sort. In two British series, without particular selection for problems with tachyarrhythmias, there were no cases of short PR interval of any sort among the study groups of $85^{11}$ and $182^{12}$ subjects with mitral valve prolapse.

Problems of cardiac impulse formation and conduction are also encountered in subjects with mitral valve prolapse. ${ }^{3315657}$ Sixty symptomatic patients with mitral valve prolapse underwent electrophysiological study; 49 had documented arrhythmias and 28 had experienced syncope. ${ }^{57}$ Spontaneous second or third degree atrioventricular block was documented in eight patients, and 10 had chronic bundle branch block. Electrophysiological study showed abnormal sinus node function in eight patients, prolonged $\mathrm{HV}$ interval in 10, intra-Hisian delay in nine, and functional bundle branch block in 15. Dual atrioventricular nodal pathways were detected in 24 patients. Comparison with 101 similarly symptomatic patients without mitral valve prolapse showed a greater prevalence of dual atrioventricular nodal pathways and functional bundle branch block in the patients with mitral valve prolapse, but the other features were not significantly more or less common in the control group and therefore probably represent casual coincidence with mitral valve prolapse.

\section{Association with thoracic spine and chest wall abnormalities}

Narrow anteroposterior chest diameter, straight back, and pectus excavatum deformity are commonly associated with mitral valve prolapse. ${ }^{331,58-62}$ The mitral valve undergoes differentiation to its final form 
between the thirty fifth and forty second day of fetal development, when the vertebral column and thoracic cage are beginning their chondrification and ossification. Any influence on fetal development at this stage may therefore affect both the mitral valve and bony thorax. ${ }^{58}$ In one radiological study in Hong Kong the metacarpal index was also measured, and, somewhat surprisingly, among the study group of 115 subjects with mitral valve prolapse almost all with abnormal metacarpal indices had normal chest measurements (ratio of anteroposterior to transverse diameter) ${ }^{62}$; the reason for this dissociation is obscure, but it does suggest that in respect of aetiology subjects with mitral valve prolapse are likely to be heterogeneous and that a substantial proportion are unlikely to have anything to do with Marfan's syndrome.

Breast development may be impaired in some women with mitral valve prolapse, and the explanation could be similar to that for abnormalities of the bony thorax associated with mitral valve prolapsenamely, that both breast and mitral valve are of mesenchymal origin and undergo simultaneous primordial development. ${ }^{63}$ In a group of 27 patients with hypomastia referred for elective augmentation mammoplasty, $13(48 \%)$ had mitral valve prolapse on both $M$ mode and cross sectional echocardiograms compared with only two (6\%) of 33 controls. ${ }^{63}$ Conversely, of 28 women selected consecutively from the echocardiographic data base at the same medical centre during the same 14 month period with mitral valve prolapse shown on echocardiography, $17(61 \%)$ had hypomastia; hypomastia was found in eight (24\%) of the controls. Whether the explanation for the link between hypomastia and mitral valve prolapse is entirely explicable in terms of embryological and mesenchymal dysplasia is a matter of dispute. ${ }^{64}$ With a much higher prevalence of mitral valve prolapse among lean persons than among those of above average body weight in the Framingham study ${ }^{9}$ and with other data indicating a correlation with slim build and below average weight, ${ }^{46164}$ the hypomastia may simply be due to reduced contribution of adipose tissue to breast size. ${ }^{64}$

Clinicians should be aware of the increased chance that mitral valve prolapse is present when thoracic skeletal deformities or hypomastia (defined as a breast size $\leqslant 200 \mathrm{ml}^{63}$ ) are present. Familial clustering of cases of mitral valve prolapse does occur, ${ }^{365-67}$ but, although there is some evidence of an autosomal dominant mode of inheritance, ${ }^{3616667}$ it appears that convincing proof of this hypothesis is lacking at present. ${ }^{968}$ Nevertheless, diagnostic appraisal of possible mitral valve prolapse in the potentially affected close relatives of subjects with primary mitral valve prolapse seems warranted. ${ }^{68}$
Association with inherited disorders characterised by weakness or laxity of certain tissues

It is well established that mitral valve prolapse is an integral part of many inherited connective tissue disorders, ${ }^{34} 3168$ best known among which are the Marfan and Ehlers-Danlos syndromes.

In an $\mathbf{M}$ mode echocardiographic study of 35 patients with the Marfan syndrome mitral valve prolapse was found in $91 \% .{ }^{69}$ In 50 consecutive patients with the syndrome reported by Pyeritz and McKusick, 24 (48\%) had midsystolic clicks with or without late systolic murmurs and 29 (58\%) had echocardiographic (probably $M$ mode for most cases, although not specified) evidence of mitral valve prolapse. ${ }^{70}$ Among 13 patients with typical Marfan's syndrome, fusiform aneurysms of the ascending aorta, and chronic aortic regurgitation studied at necropsy ${ }^{71}$ mitral valve prolapse was evident in only four, but the mitral annulus was larger than normal in most of the hearts and histological examination of the mitral leaflets showed excessive acid mucopolysaccharide material in all cases. Despite the frequency with which mitral valve prolapse is encountered in those with the Marfan syndrome, and despite some tendency for mitral valve prolapse to be associated with a marfanoid habitus, ${ }^{6168}$ the suggestion ${ }^{72}$ that mitral valve prolapse represents a forme fruste of Marfan's syndrome has now been firmly rejected. ${ }^{368}$

The Ehlers-Danlos syndrome is a group of inherited defects of connective tissue sharing certain physical features such as hypermobile joints, fragile skin, bruising, hernias, and various deformities including pectus excavatum ${ }^{73}$; there are several reports of its coexistence with mitral valve prolapse. ${ }^{374-77}$ In type IV Ehlers-Danlos syndrome a propensity for aortic rupture $^{73}$ is a striking point of similarity with the Marfan syndrome. In a family with type IV EhlersDanlos syndrome cross sectional echocardiography detected mitral valve prolapse in eight of 10 subjects examined, and when production of type III collagen ${ }^{73}$ was assessed by use of cultured fibroblasts from skin biopsy specimens it was found to be deficient in all eight echopositive cases and normal in the two cases with normal echocardiograms. ${ }^{77}$ Abnormal type III collagen is the fundamental biochemical defect in Ehlers-Danlos syndrome type IV $^{73}$ and analysis of a surgically excised valve from a patient with mitral valve prolapse and severe mitral regurgitation, who did not have the Marfan or Ehlers-Danlos syndrome, has shown a pronounced deficiency of type III collagen. ${ }^{78}$ More recent data from Australia, however, have shown that in 19 myxomatous mitral valves obtained at valve replacement surgery there is increased production of several types of collagen, in 
particular type III, ${ }^{28}$ and prompts speculation that the glycosaminoglycan inflltration and cellular proliferation in the valves are part of a repair process. The microstructural basis for mitral valve prolapse may thus be different in primary mitral valve prolapse compared with the mitral valve prolapse encountered in the inherited disorders of collagen synthesis.

Hypermobility of joints has been found to be more common in 21 subjects with echocardiographically identified primary mitral valve prolapse than in matched controls, but there was no significant difference in skin thickness, skin elasticity, or prevalence of either skeletal deformity or marfanoid habitus between the groups. ${ }^{79}$ Other investigators ${ }^{12}$ have not found this undue joint mobility, but among 182 patients with $M$ mode echocardiograms showing mitral valve prolapse $22(12 \%)$ were noted to have had a herniorrhaphy in the past, perhaps indicative of a tendency for weakness of collagen common to mitral valve and extracardiac tissue. ${ }^{12}$ Patients with hypermobile joints attending a rheumatology clinic were found to have auscultatory and $M$ mode echocardiographic evidence of mitral valve prolapse more frequently than control patients with normal joint mobility scores. ${ }^{80}$ Laxity of joints may be associated with a more widespread abnormality of collagen within the cardiovascular system. This is suggested by the finding of an increased aortic compliance (as measured by a continuous wave Doppler ultrasound technique) in 44 of 72 patients with the hypermobility syndrome, ${ }^{81}$ some of whom were also shown to have collagen abnormalities on biochemical analysis and electron microscopy of skin biopsy specimens.

The data cited in respect of the Marfan and Ehlers-Danlos syndromes give reasonable grounds for expecting to find mitral valve prolapse in a high proportion of patients with other generalised disorders of connective tissue, ${ }^{3}$ where structural weakness of mitral leaflets, chordae, and annular tissue would be the cause of the prolapse. This expectation is fulfilled in a study of pseudoxanthoma elasticum, ${ }^{82}$ but in osteogenesis imperfecta, despite reports of two regurgitant prolapsing mitral valves requiring replacement $^{83}$ and of one mitral valve showing severe myxomatous degeneration, ${ }^{84}$ an $M$ mode echocardiographic study of 20 patients detected mitral valve prolapse in only one. ${ }^{85} \mathrm{An}$ increased prevalence of mitral valve prolapse has been shown with cross sectional echocardiography in 15 patients with von Willebrand syndromes, among whom mitral valve prolapse was found in $60 \%$ compared with $13 \%$ of matched controls ${ }^{86}$; the concept of a linked mesenchymal dysplasia was proposed as a unifying hypothesis to explain the association of mitral valve prolapse with this vascular endothelial abnormality and with various skeletal and connective tissue dysplasias already mentioned. ${ }^{86}$

\section{Association with disorders of skeletal muscle}

Although there are several reports of an increased prevalence of mitral valve prolapse in myotonia atrophica, ${ }^{387}$ there is no clear evidence either of myxomatous degeneration of mitral valve tissue or of myocardial involvement with dysfunction localised so as to impair mitral valve function. ${ }^{87} \mathrm{~A}$ recent prospective study of 25 adults with myotonia atrophica showed that on cross sectional echocardiography mild mitral valve prolapse was present in three and moderate mitral valve prolapse in four cases. ${ }^{88}$ The significance of mitral valve prolapse in myotonia atrophica and in other muscle diseases requires further elucidation with larger series and provision of some correlative cardiac pathological data.

\section{Association with endocrine disorders}

When Jeresaty's monograph of mitral valve prolapse was published in $1979^{3}$ it contained but one reference to an associated endocrine disorder and that was to a report $^{89}$ of a single case of acromegaly with a systolic click and murmur complicated by streptococcal endocarditis. How surprising then that it should have taken until 1981 for an association with one of the more common disturbances of endocrine functionnamely, hyperthyroidism - to be reported. ${ }^{90}$ Impressed by what seemed to be a high frequency of mitral valve prolapse in patients with hyperthyroidism and aware of the evidence that adrenergic tone is increased both in hyperthyroidism ${ }^{91}$ and in symptomatic mitral valve prolapse ${ }^{492}$ clinicians at the Temple University School of Medicine in Philadelphia looked for mitral valve prolapse in $\mathbf{4 0}$ patients with hyperthyroidism. ${ }^{\mathbf{9 0}}$ The diagnosis of mitral valve prolapse depended on auscultatory and echocardiographic (both $M$ mode and cross sectional) assessment, and in only one instance (a hyperthyroid patient) was the diagnosis made on auscultatory findings alone. Sixteen of 39 (41\%) patients with Graves' disease and one patient with toxic nodular goitre had mitral valve prolapse compared with seven of $40(18 \%)$ patients in a control group. The prevalence of mitral valve prolapse did not differ significantly between those who were hyperthyroid at the time of evaluation and those who were not and seemed unrelated to the sex or race of the patient.

The link between mitral valve prolapse and hyperthyroidism is further explored in a much larger study from Israel reported in this issue of the journal ( $p$ 374-7)..$^{93}$ The investigators used both $M$ mode and cross sectional echocardiography to detect mitral valve prolapse. Among a group of 126 hyperthyroid patients there were $12(9.5 \%)$ cases of mitral valve prolapse, which is not significantly different from the 
prevalence of $5.4 \%$ in the control group of 111 subjects. When the 49 patients with Graves' disease were considered separately, however, the prevalence was $16.5 \%$, and this difference is significant. As in the American study ${ }^{90}$ it made no difference whether the patients were hyperthyroid or had become euthyroid. The prevalence of hyperthyroidism among 64 subjects with mitral valve prolapse was also assessed; in one case the laboratory tests indicated hyperthyroidism, but clinical features of hyperthyroidism were lacking.

The basis for the association between mitral valve prolapse and Graves' disease is a matter of conjecture. ${ }^{9093}$ It would seem that the valvar prolapse is not attributable to myocardial dysfunction caused by a direct effect of high concentrations of thyroid hormones, and there are no data on the gross morphology or histology of mitral valves from patients with this combination. Proof of a common autoimmune mechanism ${ }^{909394}$ would probably require immunohistological studies of mitral valve and thyroid tissue. Certain histocompatibility antigens have been reported to be associated with mitral valve prolapse ${ }^{909395}$ and with Graves' disease, ${ }^{9093}$ but the pathophysiological mechanisms by which this might cause the two disorders remain undetermined. Perhaps the best guess that can be made at present is to suppose a defect of genetic coding for control of mitral valve tissue formation, turnover, or subsequent modification at a locus adjacent to one exerting some influence over the control of thyroid function or all three. This could be the basis for some of the other clinical associations ${ }^{636886}$ and is worthy of further investigation.

\section{Conclusion}

There is still much to be learned about mitral valve prolapse,${ }^{49697}$ and in clinical practice major issues which remain imperfectly resolved include the pathogenesis and management of accompanying chest pain, ${ }^{498}$ identification and protection of those subjects at risk of thromboembolic complications ${ }^{497}$ or arrhythmic sudden death, 99100 and prophylaxis against endocarditis. ${ }^{97101}$ There is no doubt that anatomical prolapse of mitral leaflets is common, but in only a small proportion of subjects should we consider this to be "abnormal." 16 In some it will be evanescent. It may be some years before pathological studies on mitral valves from an appreciable number of supposed "normal variant" subjects with mitral valve prolapse can be reported. Improved cross sectional echocardiographic instrumentation and meticulous attention to details of technique will enable mitral leaflet thickness to be determined, as very recently reported by Chandraratna et $a l,{ }^{102}$ and this may be the key to distinguishing between "nor- mal" prolapsing mitral valves and pathological 96 forms of mitral valve prolapse. A completely new set of cross sectional echocardiographic surveys of mitral valve prolapse in unselected populations and in subgroups of patients with the various conditions suspected to be associated with mitral valve prolapse will now have to be carried out, and it is to be hoped that the opportunity will be taken, wherever possible, to ascertain the morphology, histology, and histochemistry of the mitral valve and any other features of cardiac pathology.

\section{References}

1 Criley JM, Lewis KB, Humphries JO, Ross RS. Prolapse of the mitral valve: clinical and cineangiocardiographic findings. Br Heart $\mathcal{F}$ 1966; 28: 48896.

2 Barlow JB, Pocock WA. The problem of non-ejection systolic clicks and associated mitral systolic murmurs: emphasis on the billowing mitral leaflet syndrome. Am Heart f 1975; 90: 636-55.

3 Jeresaty RM. Mitral valve prolapse. New York: Raven Press, 1979.

4 Wooley CF. The mitral valve prolapse syndrome. Hosp Pract 1983; 18: 163-74.

5 Brown OR, Kloster FE, DeMots $\mathrm{H}$. Incidence of mitral valve prolapse in the asymptomatic normal [Abstract]. Circulation 1975; 52 (suppl II): 77.

6 Markiewicz W, Stoner J, London E, Hunt SA, Popp RL. Mitral valve prolapse in one hundred presumably healthy young females. Circulation 1976; 53: 464-73.

7 Procacci PM, Savran SV, Schreiter SL, Bryson AL. Prevalence of clinical mitral valve prolapse in 1169 young women. $N$ Engl $\mathcal{F}$ Med 1976; 294: 1086-8.

8 Hickey AJ, Wilcken DEL. Prevalence of mitral valve prolapse in an Australian population [Letter]. Lancet 1980; 1: 1366.

9 Savage DD, Garrison RJ, Devereux RB, et al. Mitral valve prolapse in the general population. 1 . Epidemiologic features: The Framingham Study. Am Heart f 1983; 106: 571-6.

10 Savage DD, Devereux RB, Garrison RJ, et al. Mitral valve prolapse in the general population. 2. Clinical features: The Framingham Study. Am Heart $\mathcal{F}$ 1983; 106: 577-81.

11 Malcolm AD, Boughner DR, Kostuk WJ, Ahuja SP. Clinical features and investigative findings in presence of mitral leaflet prolapse: study of 85 consecutive patients. Br Heart $\mathcal{F}$ 1976; 38: 244-56.

12 Beton DC, Brear SG, Edwards JD, Leonard JC. Mitral valve prolapse: an assessment of clinical features, associated conditions and prognosis. Qf Med 1983; 52: $150-64$.

13 Levine RA, Weyman AE. Mitral valve prolapse: a disease in search of, or created by, its definition. Echocardiography 1984; 1: 3-14.

14 Shah PM. Update of mitral valve prolapse syndrome: when is echo prolapse a pathological prolapse? Echocardiography 1984; 1: 87-95.

15 Wann LS, Grove JR, Hess TR, et al. Prevalence of 
mitral prolapse by two dimensional echocardiography in healthy young women. Br Heart $\mathcal{f} 1983$; 49: 334-40.

16 Oakley CM. Mitral valve prolapse: harbinger of death or variant of normal? $\mathrm{Br} \mathrm{Med} \mathrm{F} \mathrm{1984;} \mathrm{288:} \mathrm{1853-4.}$

17 Morganroth J, Jones RH, Chen CC, Naito M. Two dimensional echocardiography in mitral, aortic and tricuspid valve prolapse: the clinical problem, cardiac nuclear imaging considerations and a proposed standard for diagnosis. Am F Cardiol 1980; 46: 1164-77.

18 Abbasi AS, DeCristofaro D, Anabtawi J, Irwin L. Mitral valve prolapse: comparative value of $\mathrm{M}$-mode two-dimensional and doppler echocardiography. $\mathcal{J ~ A m}$ Coll Cardiol 1983; 2: 1219-23.

19 Alpert MA, Carney RJ, Flaker GC, Sanfelippo JF, Webel RR, Kelly DL. Sensitivity and specificity of two-dimensional echocardiographic signs of mitral valve prolapse. Am f Cardiol 1984; 54: 792-6.

20 Bittar N, Sosa JA. The billowing mitral valve leaflet: report on fourteen patients. Circulation 1968; 38: 76370.

21 Leachman RD, De Francheschi A, Zamolloa O. Late systolic murmurs and clicks associated with abnormal mitral valve ring. Am f Cardiol 1969; 23: 679-83.

22 Pomerance A. Ballooning deformity (mucoid degeneration) of atrioventricular valves. Br Heart $\mathcal{F} 1969$; 31: 343-51.

23 Davies MJ, Moore BP, Braimbridge MV. The floppy mitral valve: study of incidence, pathology, and complications in surgical, necropsy, and forensic material. $\mathrm{Br}$ Heart $\mathcal{F} 1979$; 40: 468-81.

24 Olsen EGJ, Al-Rufaie HK. The floppy mitral valve: study on pathogenesis. Br Heart F 1980; 44: 674-83.

25 Rippe J, Fishbein MO, Carabello B, et al. Primary myxomatous degeneration of cardiac valves: clinical, pathological, haemodynamic, and echocardiographic profile. Br Heart f 1980; 44: 621-9.

26 King BD, Clark MA, Baba N, Kilman JW, Wooley CF. "Myxomatous" mitral valves: collagen dissolution as the primary defect. Circulation 1982; 66: 288-96.

27 Roberts WC. Morphologic features of the normal and abnormal mitral valve. Am $\mathcal{F}$ Cardiol 1983; 51: 1005-28.

28 Cole WG, Chan D, Hickey AJ, Wilcken DEL. Collagen composition of normal and myxomatous human mitral heart valves. Biochem $\mathcal{F}$ 1984; 219: 451-60.

29 Wilcken DEL, Hickey AJ, Cole WG, Chan D. The pathogenesis of the floppy mitral valve [Abstract]. Circulation 1984; 70 (suppl II): 102.

30 Becker AE, De Wit APM. Mitral valve apparatus: a spectrum of normality relevant to mitral valve prolapse. Br Heart f 1979; 42: 680-9.

31 Criley JM, Heger J. Prolapsed mitral leaflet syndrome. Cardiovasc Clin 1979; 10: 213-33.

32 Barlow JB, Pocock WA, Obel IWP. Mitral valve prolapse: primary, secondary, both or neither? Am Heart $\mathcal{F}$ 1981; 102: 140-3

33 Rippe JM, Sloss LJ, Angoff G, Alpert JS. Mitral valve prolapse in adults with congenital heart disease. Am Heart f 1979; 97: 561-73.

34 Angel J, Soler-Soler J, Garcia Del Castillo H, Anivarro I, Batlle-Diaz J. The role of reduced left ventricular enddiastolic volume in the apparently high prevalence of mitral valve prolapse in atrial septal defect. Eur $\mathcal{J}$
Cardiol 1980; 11: 341-55.

35 Leachman RD, Cokkinos DV, Cooley DA. Association of ostium secundum atrial septal defects with mitral valve prolapse. Am $\mathcal{F}$ Cardiol 1976; 38: 167-9.

36 Yazawa Y. Mitral valve prolapse related to geometrical changes of the heart in cases of progressive muscular dystrophy. Clin Cardiol 1984; 7: 198-204.

37 Barlow JB, Pocock WA. Mitral valve prolapse, the specific billowing mitral leaflet syndrome, or an insignificant non-ejection systolic click. Am Heart $\mathcal{J}$ 1979; 97: 277-85.

38 Bjerregaard P, Peterson ELC. Type A WPW and mitral valve prolapse [Letter]. Circulation 1977; 56: 136-7.

39 Schmaltz AA, Ibrahim ZI, Apitz J. Clinical and angioand echocardiographic findings in 45 children with mitral valve prolapse syndrome. Eur $\mathcal{F}$ Cardiol 1978; 7: 49-58.

40 Lucas RV Jr, Edwards JE. Floppy mitral valve and ventricular septal defect: an anatomic study. $\mathcal{A m}$ Coll Cardiol 1983; 1: 1337-47.

41 Cabin HS, Roberts WC. Ebstein's anomaly of the tricuspid valve and prolapse of the mitral valve. Am Heart f 1981; 101: 177-80.

42 Roberts WC, Glancy DL, Seningen RP, Maron BJ, Epstein SE. Prolapse of the mitral valve (floppy valve) associated with Ebstein's anomaly of the tricuspid valve. Am $\mathcal{F}$ Cardiol 1976; 38: 377-82.

43 Gooch AS, Maranhão V, Scampardonis G, Cha SD, Yang SS. Prolapse of both mitral and tricuspid leaflets in systolic murmur-click syndrome. $N$ Engl $\mathcal{f} \mathrm{Med}$ 1972; 287: 1218-22.

44 Maranhão V, Gooch AS, Yang SS, Sumathisena DR, Goldberg HH. Prolapse of the tricuspid leaflets in the systolic murmur-click syndrome. Cathet Cardiovasc Diagn 1975; 1: 81-90.

45 Chandraratna PAN, Lopez JM, Fernandez JJ, Cohen LS. Echocardiographic detection of tricuspid valve prolapse. Circulation 1975; 51: 823-6.

46 Werner JA, Schiller NB, Prasquier R. Occurrence and significance of echocardiographically demonstrated tricuspid valve prolapse. Am Heart $\mathcal{F}$ 1978; 96: 180-6.

47 Ogawa S, Hayashi J, Sasaki H, et al. Evaluation of combined valvular prolapse syndrome by twodimensional echocardiography. Circulation 1982; 65: 174-80.

48 Brown AK, Anderson V. Two dimensional echocardiography and the tricuspid valve: leaflet definition and prolapse. Br Heart f 1983; 49: 495-500.

49 Rodger JC, Morley P. Abnormal aortic valve echoes in mitral prolapse: echocardiographic features of floppy aortic valve. Br Heart F 1982; 47: 337-43.

50 Roberts WC. Aneurysm (redundancy) of the atrial septum (fossa ovale membrane) and prolapse (redundancy) of the mitral valve. Am F Cardiol 1984; 54: 1153-4.

5.1 Iliceto S, Papa A, Sorino M, Rizzon P. Combined atrial septal aneurysm and mitral valve prolapse: detection by two-dimensional echocardiography. Am $\mathcal{F}$ Cardiol 1984; 54: 1151-3.

52 Gallagher JJ, Gilbert M, Svenson RH, Sealy WC, Kasell J, Wallace AG. Wolff-Parkinson-White syndrome: the problem, evaluation, and surgical correction. Circulation 1975; 51: 767-85. 
53. Krikler D, Curry P, Kafetz K. Pre-excitation and mitral valve prolapse. $\mathrm{Br}$ Med f 1976; 1: 1257.

54 Josephson ME, Horowitz LN, Kastor JA. Paroxysmal supraventricular tachycardia in patients with mitral valve prolapse. Circulation 1978; 57: 111-5.

55 Chen WWC, Wong PHC, Chow JSF. Mitral valve prolapse and pre-excitation. PACE 1982; 5: 773-5.

56 DeSilva RA, Shubrooks SJ Jr. Mitral valve prolapse with atrioventricular and sinoatrial node abnormalities of long duration. Am Heart $\mathcal{F}$ 1977; 93: 772-5.

57 Ware JA, Magro SA, Luck JC, et al. Conduction system abnormalities in symptomatic valve prolapse: an electrophysiologic analysis of 60 patients. Am $\mathcal{F}$ Cardiol 1984; 53: 1075-8.

58 Bon Tempo CP, Ronan JA Jr, de Leon AC Jr, Twigg HL. Radiographic appearance of the thorax in systolic click-late systolic murmur syndrome. Am $\mathcal{F}$ Cardiol 1975; 36: 27-31.

59 Salomon J, Shah PM, Heinle RA. Thoracic skeletal abnormalities in idiopathic mitral valve prolapse. $A m \mathcal{F}$ Cardiol 1975; 36: 32-6.

60 Udoshi MB, Shah A, Fisher VJ, Dolgin M. Incidence of mitral valve prolapse in subjects with thoracic skeletal abnormalities-a prospective study. Am Heart $\mathcal{F}$ 1979; 97: 303-11.

61 Schutte JR, Gaffney FA, Blend L, Blomqvist CG. Distinctive anthropometric characteristics of women with mitral valve prolapse. Am 7 Med 1981; 71: 533-8.

62 Chan FL, Chen WWC, Wong PHC, Chow JSF. Skeletal abnormalities in mitral-valve prolapse. Clin Radiol 1983; 34: 207-13.

63 Rosenberg CA, Derman GH, Grabb WC, Buda AJ. Hypomastia and mitral-valve prolapse: evidence of a linked embryologic and mesenchymal dysplasia. $N$ Engl f Med 1983; 309: 1230-2.

64 Devereux RB, Lutas EM, Kramer-Fox R, Brown WT. Hypomastia and mitral-valve prolapse [Letter]. $N$ Engl f Med 1984; 310: 1053-4.

65 Rizzon P, Biasco G, Brindicci G, Mauro F. Familial syndrome of midsystolic click and late systolic murmur. Br Heart f 1973; 35: 245-59.

66 Weiss AN, Mimbs JW, Ludbrook PA, Sobel BE. Echocardiographic detection of mitral valve prolapse: exclusion of false positive diagnosis and determination of inheritance. Circulation 1975; 52: 1091-6.

67 Chen WWC, Chan FL, Wong PHC, Chow JSF. Familial occurrence of mitral valve prolapse: is this related to the straight back syndrome? Br Heart $\mathcal{f}$ 1983; 50: 97100.

68 Beighton P. Mitral valve prolapse and a marfanoid habitus. $\mathrm{Br}$ Med F 1982; 284: 920.

69 Brown OR, DeMots H, Kloster FE, Roberts A, Menashe VD, Beals RK. Aortic root dilatation and mitral valve prolapse in Marfan's syndrome. Circulation 1975; 52: 651-7.

70 Pyeritz RE, McKusick VA. The Marfan syndrome: diagnosis and management. $N$ Engl f Med 1979; 300: 772-7.

71 Roberts WC, Honig HS. The spectrum of cardiovascular disease in the Marfan syndrome: a clinicomorphologic study of 18 necropsy patients and comparison to 151 previously reported necropsy patients.
Am Heart 7 1982; 104: 115-35.

72 Read RC, Thal AP, Wendt VE. Symptomatic valvular myxomatous transformation (the floppy valve syndrome): a possible forme fruste of the Marfan syndrome. Circulation 1965; 32: 897-910.

73 Pope FM, Nicholls AC, Dorling J, Webb J. Molecular abnormalities of collagen: a review. $\mathcal{F} R$ Soc Med 1983; 76: 1050-62.

74 Brandt KD, Sumner RD, Ryan TJ, Cohen AS. Herniation of mitral leaflets in the Ehlers-Danlos syndrome. Am $\mathcal{F}$ Cardiol 1975; 36: 524-8.

75 Cabeen WR Jr, Reza MJ, Kovick RB, Stern MS. Mitral valve prolapse and conduction defects in Ehlers-Danlos syndrome. Arch Intern Med 1977; 137: 1227-31.

76 Leier CV, Call TD, Fulkerson PK, Wooley CF. The spectrum of cardiac defects in Ehlers-Danlos syndromes, types I and III. Ann Intern Med 1980; 92: 1718.

77 Jaffe AS, Geltman EM, Rodey GE, Uitto J. Mitral valve prolapse: a consistent manifestation of Type IV Ehlers-Danlos syndrome. Circulation 1981; 64: 121-5.

78 Hammer D, Leier CV, Baba N, Vasko JS, Wooley CF, Pinnell SR. Altered collagen composition in a prolapsing mitral valve with ruptured chordae tendineae. $A m \mathcal{F}$ Med 1979; 67: 863-6.

79 Pitcher D, Grahame R. Mitral valve prolapse and joint hypermobility: evidence for a systemic connective tissue abnormality? Ann Rheum Dis 1982; 41: 352-4.

80 Grahame R, Edwards JC, Pitcher D, Gabell A, Harvey W. A clinical and echocardiographic study of patients with the hypermobility syndrome. Ann Rheum Dis 1981; 40: 541-6.

81 Child A, Symmons D, Light N, Dyson M, Dorrance D, Grahame R. Collagen deficiency in joint hypermobility syndrome [Abstract]. Br F Rheumatol 1984; 23: 133-4.

82 Lebwohl MG, Distefano D, Prioleau PG, Uram M, Yannuzzi LA, Fleischmajer R. Pseudoxanthoma elasticum and mitral-valve prolapse. $N$ Engl f Med 1982; 307: 228-31.

83 Wood SJ, Thomas J, Braimbridge MV. Mitral valve disease and open heart surgery in osteogenesis imperfecta tarda. Br Heart $\mathcal{F}$ 1973; 35: 103-6.

84 Stein D, Kloster FE. Valvular heart disease in osteogenesis imperfecta. Am Heart 7 1977; 94: 637-41.

85 White NJ, Winearls CG, Smith R. Cardiovascular abnormalities in osteogenesis imperfecta. Am Heart $\mathcal{F}$ 1983; 106: 1416-20.

86 Pickering NJ, Brody JI, Barrett MJ. Von Willebrand syndromes and mitral-valve prolapse. $N$ Engl $\mathcal{F}$ Med 1981; 305: 131-4.

87 Gottdiener JS, Hawley RJ, Gay JA, DiBianco R, Fletcher RD, Engel WK. Left ventricular relaxation, mitral valve prolapse, and intracardiac conduction in myotonia atrophica: assessment by digitized echocardiography and noninvasive His bundle recording. $\mathrm{Am}$ Heart $\mathcal{F}$ 1982; 104: 77-85.

88 Perloff JK, Stevenson WG, Roberts NK, Cabeen W, Weiss $\mathrm{J}$. Cardiac involvement in myotonic muscular dystrophy (Steinert's disease): a prospective study of 25 patients. Am $\mathcal{F}$ Cardiol 1984; 54: 1074-81.

89 Jugdutt B, Basualdo C, Freeman H, Crockford P. Acromegaly, the systolic click syndrome, and Group D 
streptococcal endocarditis. Chest 1976; 69: 690-2.

90 Channick BJ, Adlin EV, Marks AD, et al. Hyperthyroidism and mitral-valve prolapse. $N$ Engl $\mathcal{f}$ Med 1981; 305: 497-500.

91 Grossman W, Robin NI, Johnson LW, Brooks H, Selenkow HA, Dexter L. Effects of beta blockade on the peripheral manifestations of thyrotoxicosis. Ann Intern Med 1971; 74: 875-9.

92 Boudoulas H, Reynolds JC, Mazzaferri E, Wooley CF. Metabolic studies in mitral valve prolapse syndrome: a neuroendocrine-cardiovascular process. Circulation 1980; 61: 1200-5.

93 Brauman A, Algom M, Gilboa Y, Ramot Y, Golik A, Stryjer D. Mitral valve prolapse in hyperthyroidism of two different origins. Br Heart $\mathcal{f}$ 1985; 53: 374-7.

94 Schlant RC, Felner JM, Miklozek CL, Lutz JF, Hurst JW. Mitral valve prolapse. $D M$ 1980; 26: $1-51$.

95 Braun WE, Ronan J, Schacter B, Gardin J, Isner J, Grecek D. HLA antigens in mitral valve prolapse. Transplant Proc 1977; 9: 1869-71.

96 Perloff JK. Evolving concepts of mitral-valve prolapse. $N$ Engl f Med 1982; 307: 369-70.
97 Malcolm AD. Mitral leaflet prolapse. Eur Heart f 1984; 5 (suppl A): 127-30.

98 Saltissi S, Crowther A, Byrne C, Clarke S, Jenkins BS, Webb-Peploe MM. The effects of oral digoxin therapy in primary mitral leaflet prolapse. Eur Heart $\mathcal{F}$ 1983; 4: 828-37.

99 Savage DD, Levy D, Garrison RJ, et al. Mitral valve prolapse in the general population. 3. Dysrrhythmias: The Framingham Study. Am Heart f 1983; 106: 582-6.

100 Mason DT, Lee G, Chan MC, DeMaria AN. Arrhythmias in patients with mitral valve prolapse: types, evaluation, and therapy. Med Clin North Am 1984; 68: $1039-49$.

101 Bor DH, Himmelstein DU. Endocarditis prophylaxis for patients with mitral valve prolapse: a quantitative analysis. $A m \mathcal{F}$ Med 1984; 76: 711-7.

102 Chandraratna PAN, Nimalasuriya A, Kawanishi D, Duncan P, Rosin B, Rahimtoola SH. Identification of the increased frequency of cardiovascular abnormalities associated with mitral valve prolapse by twodimensional echocardiography. Am $\mathcal{F}$ Cardiol 1984; 54: $1283-5$. 